\title{
Cancer risks in the optical manufacturing industry
}

\author{
J-D WANG, D H WEGMAN, AND T J SMITH
}

From the Occupational Health Program, Department of Physiology, Harvard School of Public Health, Boston, Mass 02115, USA

\begin{abstract}
A mortality odds ratio (MOR) study has been conducted to explore the cancer risks of exposures experienced in the production of optical lenses and metal spectacle frames. Male death certificates were obtained from a Massachusetts town where a large optical industry is located. Craftsmen, foremen, and operatives of non-optical industries, such as woollen textile workers and workers in the optical company with short-term or no exposure, were chosen as reference workers because their incomes were similar to those of the exposed workers. Cardiovascular disease (total 714) is chosen as the reference disease to explore cancers (total 232). An excess risk of total cancers (observed $=70$, expected $=48$ ) has formed among lens workers. The excess may be accounted for mainly by the excess risk of gastrointestinal cancers; the standardised MORs (sMOR) for medium and long-term exposure were $2 \cdot 2$ and $2 \cdot 5$. The excess was especially evident for colorectal cancers; the sMORs for medium and long-term exposures were 3.2 and $2 \cdot 6$. Excess risks of gastrointestinal cancers $(\mathrm{sMOR}=2 \cdot 9)$ and colorectal cancers $(\mathrm{sMOR}=3 \cdot 4)$ were found among metal frame workers with long-term (employed for more than 29 years) exposure, but the number of exposed cases was small ( 9 and 6 respectively). These results suggest that exposure to abrasives or cutting oil mists or both, possibly by ingestion, might increase the risk of gastrointestinal (especially colorectal) cancers among lens and metal spectacle frame manufacturers.
\end{abstract}

For over half a century, workers in the optical industry who manufacture lenses have been routinely exposed to pitch and abrasives during lens blocking, grinding, and polishing operations. ${ }^{1}$ The pitch, which formerly came from coal tar, might contain carcinogens. ${ }^{2-4}$ It has been suggested recently that the abrasives, composed mainly of metal oxides (such as ferric oxide, cerium oxide, and zirconium oxide) and silica, carborundum, or corundum, could be associated with excess digestive cancer. ${ }^{5}$ Although dermatitis was reported as an occupational hazard among lens workers, ${ }^{1}$ there have been few reports on possible cancer risks linked to lens manufacturing.

The manufacturing of metal spectacle frames is an operation performed in some optical industries. These metal working processes (metal cutting, polishing, and electroplating) have been associated with the increase of gastrointestinal cancer in other industrial settings. ${ }^{67}$

A large optical company, located in a Massachusetts town, includes both the lens and metal

Received 10 May 1982

Accepted 23 July 1982 frame manufacturing processes. The town death registry provided us with the opportunity to examine various cancer risks among workers engaged in these two operations. The use of the mortality odds ratio (MOR) ${ }^{8}$ in this study also shows how this method may be applied to investigate occupational disease.

\section{Material and methods}

\section{DATA COLLECTION}

Death certificates of all white men aged 18 or over who died between 1956 and 1975 in the town under study were reviewed. Age, ethnic information, date of death, occupational title, employer's name, and the underlying cause of death were abstracted from the death certificate. Any decedent with cancer recorded either as an underlying cause of death or as an "other significant condition" was counted as a case of cancer. The cause of death for each decedent was coded according to the 8th revision of the International Classification of Diseases. ${ }^{9}$ Each occupational title was coded according to the 1960 Classified Index of Occupations and Industries ${ }^{10}$ 
with some minor modification. Some company names were also coded if specified.

The list of the deceased was compared with the employee files of the optical company, which employs about $90 \%$ of the optical workers in town. Files are kept on all who have worked for more than one week at the company. A flood in August 1955, however, destroyed all the files on those who had retired and those who were not currently working. So, of 519 decedants listed on the death certificates as formerly employed at the company, we obtained $288(55 \%)$ complete work histories. We also identified 168 decedents who had once worked for the optical company but had other employers' names recorded on their death certificates.

\section{DEFINITION OF THE EXPOSURE VARIABLE}

The work history from the optical company consists of periods worked in each of 17 different departments. All of the production jobs associated with manufacturing lens and metal spectacle frames took place in two large departments: the lens and metal frame departments, respectively. We categorised the exposure for all jobs in the lens production department into three groups: the short-term exposure group comprised those who had worked for under two years; medium term, 2-19 years; and long term, over 19 years. In the metal frame manufacturing department the short-term exposure group was defined as those who had worked for under five years; medium-term, 5-29 years; and long-term, over 29 years. The choice of two years as the lower limit of exposure in the lens department was based on the following facts: 60 of the 117 decedents with the job title optical worker have work histories. They showed a median of two $($ mean $=13)$ years in lens production and a median of $0($ mean $<8)$ years in each of other 16 departments. The choice of five years as the lower limit of exposure in the metal frame department was based on the desire to compare results with two other epidemiological studies of metal machining. ${ }^{67}$ The categorisation of medium and long terms was based largely on equally distributed numbers in each category to obtain more statistical efficiency.

For optical workers without any work history, we assigned their exposure status according to the median duration of employment of workers with the same job title but who had work histories. There were 13 job titles on the death certificates (totally, 16 decedents) for which no other decedents with comparable job titles had work histories. After consulting the personnel department of the company and an industrial hygienist, we assigned each of these job titles an exposure category, and they were included in the study.
SELECTION OF REFERENCE WORKERS AND REFERENCE DISEASES

Because we are interested in cancer risks, ideal reference workers should not only be unexposed to the emissions from the process under study but also should have similar smoking, diet, or socioeconomic patterns, or a combination of these, as the exposed workers. We chose woollen textile workers, craftsmen, foremen, and operatives from other manufacturing, construction, or transport industries, and optical workers with none or short-term exposure to both lens and metal frame manufacturing as reference workers because their salaries (table 1) and the physical demands of their jobs are similar to those of the exposed optical workers. Non-exposed optical workers holding administrative or scientific jobs such as managers, accountants, lawyers, scientists, or mechanical engineers were excluded from reference workers because they are higher in socioeconomic status and their jobs are more sedentary. Pipe fitters and automechanics were also excluded because they might have a higher exposure to asbestos, which might increase their risk of various cancers. We had to assume that similar socioeconomic status and physical demand of jobs would result in similar smoking patterns, ${ }^{11}{ }^{12}$ dietary habits, and self-selection into jobs for the exposed and the chosen reference workers.

To use the mortality odds ratio (MOR) as an estimate of the observed-to-expected ratio, the following assumption should be fulfilled. The reference (auxiliary) cause of death should be unrelated to any differences in occupational exposures between the exposed and reference workers. ${ }^{8}$ In other words, the exposed workers and reference workers should have similar likelihood of dying from the reference disease. Since both exposed and reference workers were not known to be exposed to any known car-

Table 1 Annual average wages paid to workers of different industries in the town under study. (Each number of dollars is calculated from the data of the Division of Employment Security, Commonwealth of Massachusetts)

\begin{tabular}{lcccc}
\hline Calendar year & 1940 & 1950 & 1960 & 1970 \\
\hline $\begin{array}{l}\text { Optical industry } \\
\text { Woollen textile } \\
\text { industry* }\end{array}$ & 1451 & 3135 & 4418 & 7647 \\
$\begin{array}{c}\text { Other } \\
\text { manufacturing }\end{array}$ & 1233 & 2881 & 4541 & 6561 \\
$\begin{array}{c}\text { industries } \\
\begin{array}{c}\text { Transport \& } \\
\text { communication } \\
\text { industry }\end{array}\end{array}$ & 1281 & 3109 & 4273 & 7915 \\
$\begin{array}{c}\text { Construction } \\
\text { industry }\end{array}$ & 1134 & 2716 & 4692 & 7615 \\
$\begin{array}{c}\text { Average No of } \\
\text { employed }\end{array}$ & 1364 & 2881 & 4150 & 7027 \\
\hline
\end{tabular}

*Number represents the average for a neighbouring town where many decedents worked. 
diovascular toxins ${ }^{13}$ - that is carbon monoxide, carbon disulphide, nitrates, cobalt, and fluorocarbons-or unusual stress, they were presumed to be of similar likelihood to die from cardiovascular disease. A review of the company's pre-employment and surveillance physical examination items, however, showed that security guards were required to have no previous or current history of cardiovascular disease in order to be hired and continuously serve this role. So, the deceased with a job title of security guard might have a deficit of deaths from cardiovascular disease and were excluded from the reference workers. Then, cardiovascular disease was chosen as the reference disease.

\section{STATISTICAL METHODS}

The statistical analyses were based on the MantelHaenszel procedure for the calculation of chi-square with one degree of freedom and the estimation of the overall rate ratio. ${ }^{14}$ The increase of effect over categories of exposure was tested according to Man- tel ${ }^{15}$ by scoring the exposure categories short term or none, medium term, and long term as 0,1 , and 2 . The test-based confidence interval ${ }^{16}$ and the standardised mortality odds ratio $^{8}$ (sMOR) were also calculated. All calculations were performed by using an HP-67 calculator with programs written by Rothman and Boice. ${ }^{17}$

\section{Results}

There are 2131 white male decedents in the town death registry from 1956 to 1975 . Among them, we found 392 cases of cancer, including 344 cases recorded as the underlying cause of death on the death certificate plus 48 cases recorded as other significant conditions. Table 2 shows the distribution of these cases of cancer among the exposed and reference workers.

Among lens workers, there are 140 decedents (74 with work histories) in the medium-term category with a median duration of exposure 7.5 years, and

Table 2 Frequency of cancers in various occupational categories. (Numbers in parentheses indicate frequency of decedents with the cancer recorded as an other significant condition)

\begin{tabular}{|c|c|c|c|c|c|}
\hline $\begin{array}{l}\text { Cancer } \\
\text { Stomach }\end{array}$ & $\begin{array}{l}\begin{array}{l}\text { Other craftsmen \& } \\
\text { operatives \& woollen } \\
\text { textile workers }\end{array} \\
12(1)\end{array}$ & $\begin{array}{l}\text { Short-term exposed } \\
\text { optical workers }\end{array}$ & $\begin{array}{l}\text { Exposed lens workers } \\
6(0)\end{array}$ & \multicolumn{2}{|c|}{ Exposed metal workers All other decedents } \\
\hline $\begin{array}{l}\text { Stomach } \\
\text { Colon } \\
\text { Rectal } \\
\text { Respiratory } \\
\text { Lymphopoietic } \\
\text { Liver } \\
\text { Pancreas } \\
\text { Other } \\
\text { Total }\end{array}$ & 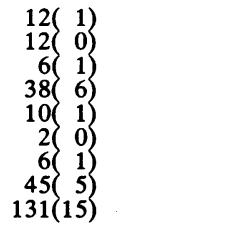 & $\begin{array}{r}5(1) \\
5(2) \\
2(0) \\
7(1) \\
2(0) \\
0(0) \\
0(0) \\
9(3) \\
30(7)\end{array}$ & 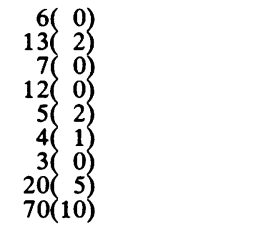 & $\begin{array}{r}3(0) \\
3(0) \\
3(0) \\
4(0) \\
0(0) \\
0(0) \\
4(1) \\
7(3) \\
24(4)\end{array}$ & 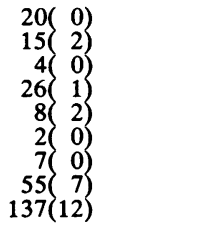 \\
\hline decedents & 752 & 138 & 286 & 128 & 827 \\
\hline
\end{tabular}

Table 3 Frequency of death from gastrointestinal cancer (GI-CA) and cardiovascular disease (CVD) according to years of employment in lens production and age

\begin{tabular}{|c|c|c|c|c|c|}
\hline \multirow[b]{2}{*}{ Age } & \multirow[b]{2}{*}{ Cause of death } & \multirow[b]{2}{*}{ Reference workers } & \multicolumn{3}{|c|}{ Lens workers } \\
\hline & & & $2-19$ years & $\geqslant 20$ years & Total \\
\hline $\begin{array}{l}60-74 \\
\geqslant 75 \\
\text { Total }\end{array}$ & $\begin{array}{l}\text { GI-CA } \\
\text { CVD } \\
\text { GI-CA } \\
\text { CVD } \\
\text { GI-CA } \\
\text { CVD } \\
\text { GI-CA } \\
\text { CVD } \\
\text { GI-CA } \\
\text { CVD }\end{array}$ & $\begin{array}{r}2 \\
17 \\
2 \\
90 \\
19 \\
224 \\
19 \\
223 \\
42 \\
554\end{array}$ & $\begin{array}{r}1 \\
4 \\
2 \\
22 \\
3 \\
27 \\
5 \\
21 \\
11 \\
74\end{array}$ & $\begin{array}{r}0 \\
2 \\
1 \\
15 \\
6 \\
42 \\
8 \\
27 \\
15 \\
86\end{array}$ & $\begin{array}{r}1 \\
6 \\
3 \\
37 \\
9 \\
69 \\
13 \\
48 \\
26 \\
160\end{array}$ \\
\hline \multicolumn{2}{|c|}{$\begin{array}{l}\text { Crude mortality odds ratio } \\
\text { Standardised mortality odds ratio (sMOR) } \\
\chi^{2}(1) \text { (Mantel-Haenszel) } \\
\chi^{2}(1) \text { (Mantel extension for the trend) } \\
\text { Rate ratio (Mantel-Haenszel) } \\
\text { point estimate } \\
90 \% \text { confidence interval }\end{array}$} & (1) & $\begin{array}{l}2 \cdot 0 \\
2 \cdot 2\end{array}$ & $\begin{array}{l}2 \cdot 3 \\
2 \cdot 5 \\
9 \cdot 3\end{array}$ & $\begin{array}{l}2 \cdot 1 \\
2 \cdot 3 \\
10 \cdot 0 \\
2 \cdot 3 \\
1 \cdot 5-3 \cdot 5\end{array}$ \\
\hline
\end{tabular}


Table 4 Frequency of death from colorectal cancer (CoRe-CA) and cardiovascular disease (CVD) according to years of employment in lens production and age

\begin{tabular}{|c|c|c|c|c|c|}
\hline \multirow[b]{2}{*}{ Age } & \multirow[b]{2}{*}{ Cause of death } & \multirow[b]{2}{*}{ Reference workers } & \multicolumn{3}{|c|}{ Lens workers } \\
\hline & & & $2-19$ years & $\geqslant 20$ years & Total \\
\hline \multirow[t]{2}{*}{$30-44$} & CoRe-CA & 1 & 1 & 0 & 1 \\
\hline & CVD & 17 & 4 & 2 & 6 \\
\hline \multirow{2}{*}{$45-59$} & CoRe-CA & 2 & 2 & 1 & 3 \\
\hline & CVD & 90 & 22 & 15 & 37 \\
\hline $60-74$ & CoRe-CA & 10 & 3 & 5 & 8 \\
\hline \multirow[t]{2}{*}{$\geqslant 75$} & CoRe-CA & $\begin{array}{r}224 \\
12\end{array}$ & $\begin{array}{r}21 \\
4\end{array}$ & $\begin{array}{r}42 \\
4\end{array}$ & $\begin{array}{r}69 \\
8\end{array}$ \\
\hline & CVD & 223 & 21 & 27 & 48 \\
\hline \multirow[t]{2}{*}{ Total } & CoRe-CA & 25 & 10 & 10 & 20 \\
\hline & CVD & 554 & 74 & 86 & 160 \\
\hline \multirow{4}{*}{\multicolumn{2}{|c|}{$\begin{array}{l}\text { Crude mortality odds ratio } \\
\text { Standardised mortality odds ratio (sMOR) } \\
\chi^{2}(1) \text { (Mantel-Haenszel) } \\
\chi^{2}(1) \text { (Mantel extension for the trend) } \\
\text { Rate ratio (Mantel-Haenszel) }\end{array}$}} & (1) & $3 \cdot 0$ & $2 \cdot 6$ & $2 \cdot 8$ \\
\hline & & (1) & $3 \cdot 2$ & $2 \cdot 6$ & $2 \cdot 9$ \\
\hline & & & & 9.7 & \\
\hline & & & & & \\
\hline \multicolumn{2}{|c|}{$\begin{array}{l}\text { point estimate } \\
90 \% \text { confidence interval }\end{array}$} & & & & $\begin{array}{l}2 \cdot 9 \\
1.8-4 \cdot 8\end{array}$ \\
\hline
\end{tabular}

146 decedents (97 with work histories) in the longterm category with a median duration of exposure of 37 years. An excess risk of total cancers (observed/ expected $=70 / 48=1.5$ ) was found to result mainly from the excess risk of gastrointestinal cancers (table 3), especially the colorectal cancers (table 4). The sMORs or respiratory cancer among the medium and long-term categories were 1.1 and 0.7 ; for stomach cancer 0.2 and 2.3 ; and for lymphopoietic cancer 2.5 and 0.9 . There was no significant risk difference relative to the reference workers for the last three types of cancer (all of them $p>0 \cdot 1$ ). A dose-response trend was observed for gastrointestinal cancers because of the combination of a general excess of colorectal cancer among the exposed and a possible excess of stomach cancer among long-term workers.
Among workers in the metal frame department, 72 decedents (46 with job histories) in the mediumterm category had a median duration of exposure of $15 \cdot 5$ years and 56 decendents ( 42 with job histories) in the long-term category a median duration of exposure of 42.5 years. There was no significant increase in risk for total cancers, gastrointestinal cancers, or colorecral cancers if the medium and long-term workers were combined as a single exposure category (all of them $\mathrm{p}>0 \cdot 1$ ). The sMORs of gastrointestinal cancers for medium and long-term exposures, however, were 0.4 and 2.9 with a Mantel extention for the trend chi-square = $3.6(p=0.06)$, which suggests a possible excess among the long-term workers. The possible excess is mainly due to the excess of colorectal cancers (table 5).

Table 5. Frequency of death from colorectal cancer (CoRe-CA) and cardiovascular disease (CVD) according to years of employment in metal frame manufacturing and age

\begin{tabular}{|c|c|c|c|c|c|}
\hline \multirow[b]{2}{*}{ Age } & \multirow[b]{2}{*}{ Cause of death } & \multirow[b]{2}{*}{ Reference workers } & \multicolumn{3}{|c|}{ Metal frame workers } \\
\hline & & & $5-29$ years & 30 years & Total \\
\hline $30-44$ & CoRe-CA & 1 & 0 & 0 & 0 \\
\hline & CVD & 17 & 3 & 0 & 3 \\
\hline $45-59$ & CoRe-CA & 2 & 0 & 1 & 1 \\
\hline $60-74$ & $\begin{array}{l}\text { CVD } \\
\text { CoRe-CA }\end{array}$ & $\begin{array}{l}90 \\
10\end{array}$ & 12 & 6 & 18 \\
\hline $00-14$ & CVD & 224 & 21 & $\begin{array}{r}2 \\
11\end{array}$ & 32 \\
\hline$\geqslant 75$ & CoRe-CA & 12 & 0 & 2 & 2 \\
\hline & CVD & 223 & 15 & 15 & 30 \\
\hline Total & CoRe-CA & 25 & 1 & 5 & 6 \\
\hline & CVD & 554 & 51 & 32 & 83 \\
\hline \multirow{4}{*}{\multicolumn{2}{|c|}{$\begin{array}{l}\text { Crude mortality odds ratio } \\
\text { Standardised mortality odds ratio (sMOR) } \\
\chi^{2}(1) \text { (Mantel-Haenszel) } \\
\chi^{2}(1) \text { (Mantel extension for the trend) } \\
\text { Rate ratio (Mantel-Haenszel) }\end{array}$}} & (1) & 0.4 & $3 \cdot 5$ & 1.6 \\
\hline & & (1) & 0.4 & 3.4 & 1.7 \\
\hline & & & & 3.6 & $1 \cdot 2$ \\
\hline & & & & & \\
\hline \multicolumn{2}{|c|}{$\begin{array}{l}\text { point estimate } \\
90 \% \text { confidence interval }\end{array}$} & & & & $\begin{array}{l}1 \cdot 7 \\
0.8-3 \cdot 6\end{array}$ \\
\hline
\end{tabular}




\section{Discussion}

One has to be cautious in the interpretation of the excess risks of gastrointestinal and colorectal cancers. To examine the possibility of a clustering of familial colorectal cancers ${ }^{18}$ among exposed workers, we reviewed relevant information of all 26 patients with cancers who were classified as the exposed (including both lens and metal frame workers). The inquiry showed that each case came from a different family, although some shared the same last name. Another possible explanation might be the difference in dietary habits among exposed and reference workers, but because reference workers were selected from a similar socioeconomic level as the exposed workers, the difference might be small. Further, an exploration of the ethnic background (birthplaces of the decedents and their parents) for workers with reference disease showed little difference between lens workers and reference workers. These findings suggest that the excess risks of gastrointestinal (especially colorectal) cancers in lens production be due to the occupational exposure.

There are several possible mechanisms that may explain how abrasives or pitch, or both, might cause gastrointestinal cancers. Workers were exposed through skin contact, inhalation, and ingestion. While hydrocarbons in pitch could be absorbed through the skin, the dermal contact with the abrasives probably does not have any harmful systemic effect. Because both abrasives and pitch were used in lens production under continuous water cooling, the amount of exposure through inhalation may have been small. Nevertheless, workers may ingest both abrasives and pitch through contaminated food and drink because their hands were constantly and heavily exposed. The observation that there was no excess risk of lung cancer for lens workers is compatible with the above mechanisms. As asbestos ${ }^{19}$ and silica $^{20}$ both enhance the membrane uptake of polyaromatic hydrocarbons in cells, abrasives may also enhance the gastrointestinal uptake of carcinogenic material ingested with food.

The increase of gastrointestinal (especially colorectal) cancers among metal spectacle frame workers in the long-term group is consistent with two previous studies of machinists ${ }^{67}$ in which the excess of stomach or bowel cancers, or both, was attributed to the exposure of cutting oil mists. Because metal grinding and polishing also entail exposure to abrasives, however, it is not possible to tell whether one or both are risk indicators. Recently, a large proportion of industries have shifted from the use of lipid soluble cutting oils to water soluble ones, which contain less polyaromatic hydrocarbons but in some cases may contain nitrosamines. ${ }^{21}$ If metal workers exposed to predominantly water soluble cutting oils (without nitrosamines) still show an excess of gastrointestinal cancer, then we probably should consider abrasives to be the main risk indicator.

\section{References}

'Horne DF. Optical production technology. New York: Crane, Russak, \& Company Inc, 1972.

${ }^{2}$ Lloyd JW. Long term mortality study of steel workers. V. Respiratory cancer in coke plant workers. JOM 1971;13:5368.

${ }^{3}$ Doll R, Vassey MP, Beasley RWR, et al. Mortality of gasworkers: final report of a prospective study. $\mathrm{Br} J$ Ind Med 1972;29:394-406.

4 Mazumdar S, Redmond C, Sollecito W, Sussman N. An epidemiological study of exposure to coal tar pitch volatiles among coke oven workers. J Air Pollut Control Assoc 1975;25:382-9.

${ }^{5}$ Wegman DH, Eisen EA. Cause of death among employees of a synthetic abrasive product manufacturing company. JOM 1981;23:748-54.

- Decoufle P. Further analysis of cancer mortality patterns among workers exposed to cutting oil mists. Journal of the National Cancer Institute 1978;61:1025-30.

7 Jarvholm B, Lillienberg L, Sallsten G, Thiringer G, Axelson O. Cancer morbidity among men exposed to oil mist in the metal industry. JOM 1981;23:333-7.

${ }^{8}$ Miettinen OS, Wang JD. An alternative to the proportionate mortality ratio. Am J Epidemiol 1981;114:144-8.

9 National Center for Health Statistics, Public Health Service. Eighth revision of the international classification of diseases, adapted for use in the United States. Washington, DC: Government Printing Office, 1968.

${ }^{10}$ US Bureau of the Census. Classified index of occupations and industries, 1960 census of population. Washington, DC: US Government Printing Office, 1960.

"Sterling TD, Weinkam JJ. Smoking characteristics by type of employment. JOM 1976;18:743-54.

${ }^{12}$ Covey LS, Wynder EL. Smoking habits and occupational status. JOM 1981;23:537-42.

${ }^{13}$ Rosenman KD. Cardiovascular disease and environmental exposure. Br J Ind Med 1979;36:85-97.

${ }^{14}$ Mantel N, Haenszel W. Statistical aspects of the analysis of data from retrospective studies of disease. Journal of the National Cancer Institute 1959;23:719-48.

${ }^{15}$ Mantel N. Chi-square tests with one degree of freedom: extensions of the Mantel-Haenzsel procedure. Journal of the American Statistical Association 1963;59:690-700.

${ }^{10}$ Miettinen OS. Estimability and estimation in case-referent studies. Am J Epidemiol 1976;103:226-35.

17 Rothman KJ, Boice JD. Epidemiologic analysis with a programmable calculator. Washington DC: US Department of Health, Education, and Welfare, Public Health Service, National Institute of Health, 1978.

18 Correa P, Haenzsel W. The epidemiology of large bowel cancer. Adv Cancer Res 1978;26:1-141.

${ }^{19}$ Lakowicz JR, Hylden JL. Asbestos-mediated membrane uptake of benzo(a)pyrene observed by fluorescence spectroscopy. Nature 1978;275:446-8.

${ }^{20}$ Lakowicz JR, McNamara M, Steenson L. Particle-mediated membrane uptake of chemical carcinogens studied by fluorescence spectroscopy. Science 1978;199:305-7.

${ }^{21}$ Fan TY, Morrison J, Rounbehler DP, et al. $\mathrm{N}$-nitrosodiethanolamine in synthetic cutting fluids: a partper-hundred impurity. Science 1977;196:70-1. 